\title{
Universidade corporativa em bancos
}

\section{Resumo}

Este artigo é um extrato de uma pesquisa detalhada a respeito dos reflexos da universidade corporativa na gestão do conhecimento em empresas do setor financeiro no Brasil. Tem por objetivo apresentar as práticas que tem favorecido a integração entre Universidade Corporativa (UC) e a Gestão do Conhecimento (GC), partindo de uma hipótese substantiva de que a UC deve, além dos benefícios inerentes da educação, auxiliar as corporações, que a implantaram, na GC. A pesquisa fez uso do método survey com vistas a identificar o número de bancos brasileiros comerciais, com sede na cidade de São Paulo que possuem UC e GC integrados e o tipo de esforço que foi realizado para esta harmonização, além disso evidencia as facilidades para implementação da GC em organizações que pratiquem a Educação Corporativa (EC).

\section{Abstract}

This article is an extract from a detailed survey about the consequences of the corporate university in the knowledge management in the financial sector in Brazil. Aims to present the practices that have favored the integration of Corporate University and Knowledge Management (KM), from a substantive hypothesis that Corporate University should, besides the inherent benefits of education, helping corporations, which have embedded in $K M$. The research used method survey with a view to identifying the number of commercial banks in Brazil, based in Sao Paulo that have integrated Corporate University and KM and the type of effort that was made for this harmonization, further evidence for the facilities to implement the KM in organizations practicing Corporate Education.

Palavras-chave: GC, UC, Gestão do Conhecimento, Universidade Corporativa, Banco

Keywords: KM, Knoledge Management, Corporate University, Bank

\section{Introdução}

Morin (2004) afirma que uma empresa produz objetos e serviços para o consumo. Ao produzir ela se autoproduz, produzindo também os elementos necessários à sua sobrevivência e organização, "se auto mantém, se auto repara se necessário, e, se as coisas não vão bem, auto desenvolve-se enquanto desenvolve a sua produção. Aquele que produz coisas, produz ao mesmo tempo a si próprio; o produtor é o seu próprio produto.” (p. 18)

A sociedade, por exemplo, é feita das interações dos indivíduos que a constituem. Como uma organização e uma organizadora, a própria sociedade retroage para produzir os indivíduos por meio da educação, linguagem e escola. Desta forma, os indivíduos produzem a sociedade e esta produz os indivíduos que a produzem, num ciclo espiral evolutivo. Assim,

\footnotetext{
1 Paulo Roberto Alves - Mestre Prof. pesquisador da PUCSP é Prof Pesquisador da FICS onde desde o primeiro semestre de 2012 compõe a Grupo de Pesquisa, e Inicialção Científica e a Oficina de Artigos das Faculdades Integradas Campos Salles - FICS. www.campossalles.edu.br
} 
a universidade corporativa associada à gestão do conhecimento pode, em muito, auxiliar na organização desta complexidade produtoprodutor ou, ainda, indivíduo-empresa.

Paralelamente ao surgimento das teorias da aprendizagem organizacional, assiste-se, no campo da organização do trabalho, o movimento de passagem da lógica do posto de trabalho à lógica da competência (ZARIFAN 2001, p.25). A ligação entre aprendizagem e competências, já presente em Argyris (1996), aparece estabelecida em Drejer (2000), que considera a aprendizagem organizacional como o ponto de partida natural para a formulação de um modelo de desenvolvimento de competências. Para Argyris (1996), a teoria da aprendizagem organizacional é a chave para a compreensão do desenvolvimento de competências.

A hipótese teórica que sustenta a associação pretendida parte da constatação de que aprendizagem e conhecimento são construtos elaborados de maneira distinta. Tomando o conhecimento como objeto, como "o que" dos processos cognitivos, teria o desenvolvimento das competências como intermediação processual na busca do conhecimento. Porém, tomando a competência como objeto, o fenômeno da aprendizagem é que surge como o processo, o "como" necessário à competência.

Algumas organizações têm usado recursos próprios e específicos, orientados para os objetivos estratégicos empresariais, consubstanciados em programas sob a designação de universidade corporativa. A presente pesquisa argumenta que, pelas suas especificidades, os programas das universidades corporativas (UC) são efetivos e colaboram para a gestão do conhecimento (GC) e tem como objetivo identificar o quanto a prática da UC influencia na $\mathrm{GC}$ de instituições financeiras captadoras de depósito à vista, mais especificamente bancos comerciais e caixas econômicas, cujas sedes e as mais significativas operações estão localizadas na cidade de São Paulo, maior centro financeiro do país, num determinado instante, ela não tem pretende mostrar qualquer mudança ou desenvolvimento sobre o tema. Um fenômeno particular em um determinado momento será estudado, o que torna o horizonte de tempo cross-sectional, o mais comum quando a estratégia de investigação é survey.

\section{Conhecendo os Bancos}

Constituem elementos representativos do universo populacional de pesquisa os dez maiores Bancos por patrimônio (Nacionais, Estrangeiros ou Mistos), listados no site da Febraban (2008). Neste espaço apresento a estratégia de contratação de colaboradores, a distribuição por cargo e a escolaridade, dados que nos auxiliarão no entendimento dos resultados desta pesquisa.

1.1. Estratégia de contratação e distribuição dos colaboradores por cargo

Os bancos têm como estratégia de atração e retenção de colaboradores a contratação na base para o desenvolvimento dos funcionários dentro da própria instituição financeira. Uma pesquisa realizada, pela Febraban (2009), com 15 bancos apresenta os cargos assim distribuídos. Os administrativos e operacionais somam $66 \%$ dos cargos, enquanto supervisão e coordenação $21,3 \%$ e os restantes 12,7 distribuídos entre as gerências e as diretorias. A figura 2.1 apresenta esta distribuição. 


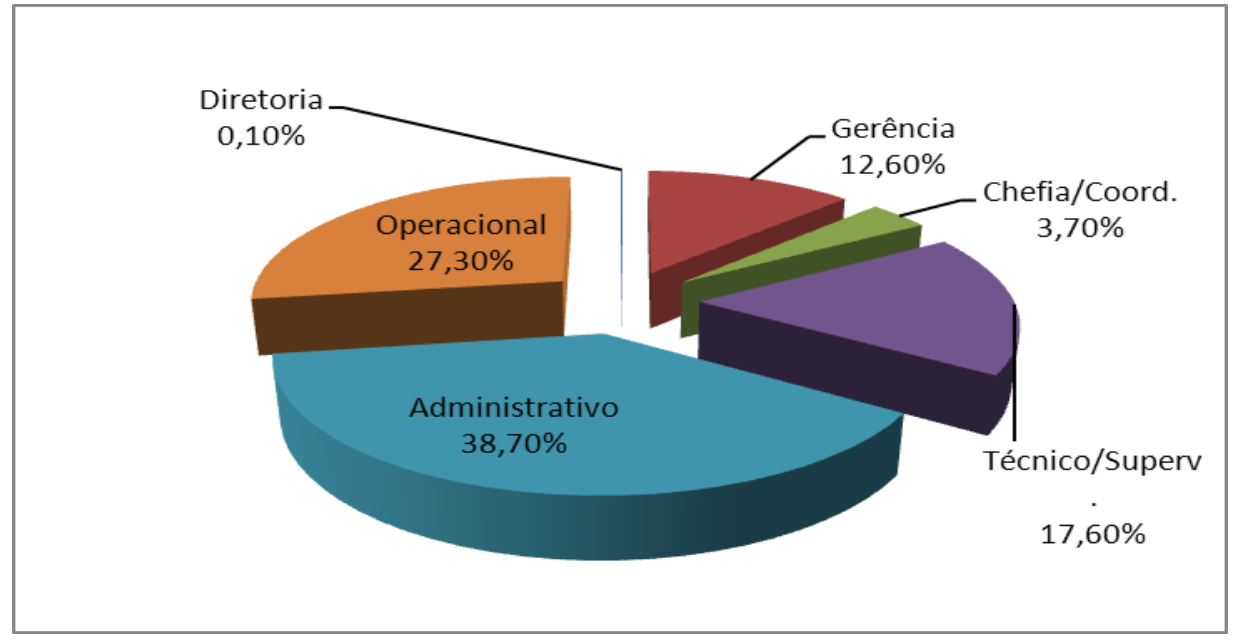

Figura 2.1 Distribuição de cargos nos Bancos Fonte: Febraban (2009) Adaptado

\section{Escolaridade}

De acordo com a pesquisa da FEBRABAN, chega a $27,4 \%$ o número de funcionários que concluíram o ensino médio ou profissional, e 18,7\% estão cursando o terceiro grau, enquanto os com graduação completa totalizam $40,8 \%$, e os pós-graduados, $10,9 \%$. No Brasil, o percentual de pessoas com mais de 18 anos de idade que supera 11 anos de instrução era de $27,2 \%$ no último levantamento populacional do IBGE, a PNAD 2005. Entre as mulheres que trabalham nos bancos, 9,5\% possuem pós-graduação, enquanto entre os homens o indicador chega a 12,1\%. Já a parcela de graduados é maior entre elas do que entre eles: $42,9 \%$ e $38,8 \%$. A figura 2.2 mostra a escolaridade dos profissionais do setor.
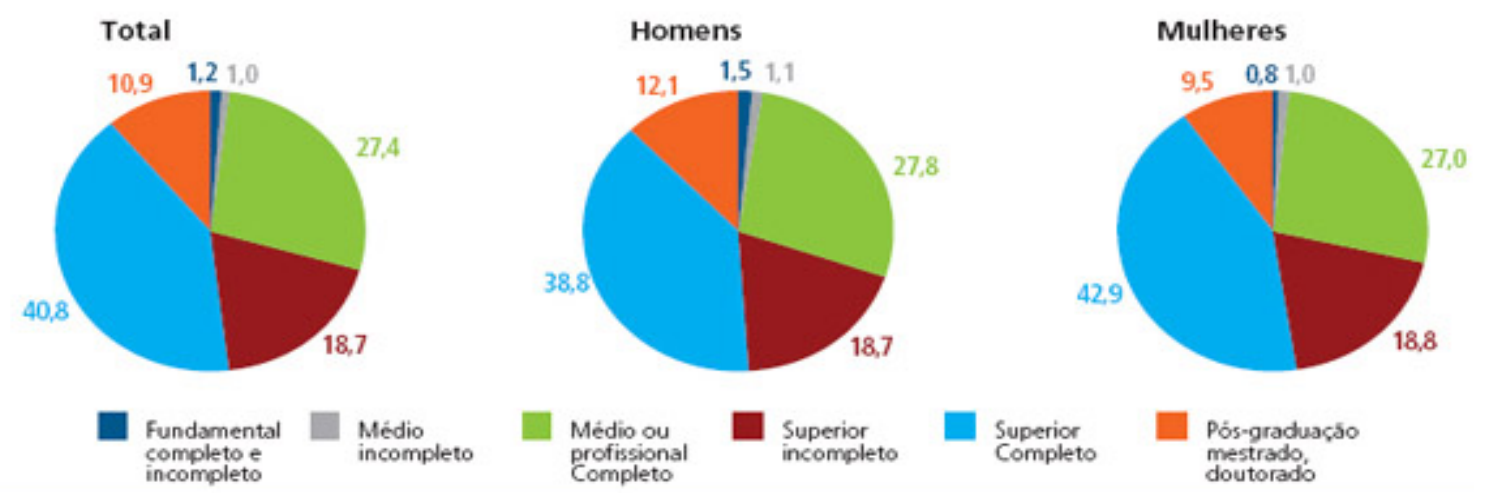

Figura 2.2 Escolaridade. Fonte: (FEBRABAN 2008).

\section{Histórico da Educação Corporativa}

As universidades nasceram nos centros do saber que na Idade Média se restringiam à
Igreja, aos mosteiros, com origem fortemente religiosa, porque os padres eram os únicos alfabetizados, os únicos que publicavam livros, e os únicos a organizarem bibliotecas. Foi 
neste ambiente onde nasceu o conceito universidade.

A Educação só se torna pública e de responsabilidade do Estado, após a revolução democrática na Inglaterra, com o Parlamentarismo Democrático e a Revolução Francesa. Este cenário dura todo o século XX. Com a democratização do saber o mundo foi se tornando mais inteligente, com necessidade de se qualificar a população para que os anseios dela mesma sejam atendidos. A sociedade, por exemplo, é feita das interações dos indivíduos que a constituem. Como uma organização e uma organizadora, a própria sociedade retroage para produzir os indivíduos por meio da educação, linguagem e escola. Desta forma, os indivíduos produzem a sociedade e esta produz os indivíduos que a produzem, num ciclo espiral evolutivo.

O mercado cada vez mais exigente e competitivo abre a necessidade de funcionários cada vez mais capazes sob todos os aspectos técnicos, gerenciais e comportamentais. As empresas atuais já perceberam o valor do capital intelectual (CI) e estão investindo cada vez mais nos seus recursos humanos. (SOUZA, 2000) afirma que o capital intelectual não aparece no balanço financeiro da empresa, mas que pode ser mensurado pela diferença entre $o$ valor patrimonial (VP) e valor de mercado $(\mathrm{VM}) . \quad \mathrm{CI}=\mathrm{VM}-\mathrm{VP}$.

De acordo com Bayma (1994), as Empresas são impulsionadas a atualizar o conhecimento dos seus trabalhadores com o uso da educação continuada ajustando as suas competências às necessidades empresariais. Uma das maneiras encontradas pelas organizações foi o uso de recursos próprios e específicos, orientados para os objetivos estratégicos empresariais, consubstanciados em programas sob a designação de universidade corporativa (UC).
Nos anos 50 em Crottonville a GE organiza a primeira Universidade Corporativa mundial, esta nova modalidade de educação tem sido aderida por um número vultoso de empresas. Em 2007, os Estados Unidos tinham aproximadamente mais de três mil universidades corporativas, com um crescimento de $10 \%$ ao ano. Se este crescimento se perdurar, em pouco tempo teremos mais universidades corporativas do que universidades tradicionais. Este crescimento se dá principalmente em função da validade do conhecimento que diminuiu e as empresas não conseguem mais dar este tempo que as universidades tradicionais necessitam para formar este novo conhecimento.

Com a globalização e a Internet as empresas não concorrem mais com as empresa do bairro, da cidade ou do estado. O seu concorrente, assim como o seu cliente, podem estar do outro lado do mundo. Desta forma, as empresas precisam estar constantemente atualizando os seus colaboradores, para que possam reagir à altura dos seus concorrentes e atender às expectativas dos seus clientes, cada vez mais exigentes.

Para Meister (1999, p.2) as empresas do século XXI são diferentes das empresas da metade do século XX. Elas são mais enxutas e flexíveis, enfrentam uma obsolescência rápida do conhecimento, estão em busca de mercados globais e não somente os domésticos, focando na necessidade do cliente ao invés do lucro em curto prazo. O quadro 3.1 mostra as diferenças entre o modelo antigo de empresa e a do século XXI. Para a autora, as Universidades Corporativas surgiram para compensar a qualidade e o conteúdo da graduação e a necessidade de um aprendizado permanente e ágil. Ela não pode mais esperar pela aprovação do Conselho Universitário e outras burocracias que a concorrência atual já se livrou. 


\begin{tabular}{|c|c|c|}
\hline Modelo Antigo & & Protótipo do século XXI \\
\hline Hierarquia & Organização & Redes de Parcerias e Alianças \\
\hline $\begin{array}{l}\text { Desenvolver a maneira } \\
\text { Atual de fazer negócios }\end{array}$ & Missão & $\begin{array}{l}\text { Criar mudanças com valor } \\
\text { Agregado }\end{array}$ \\
\hline Autocrática & Liderança & Inspiradora \\
\hline Domésticos & Mercados & Globais \\
\hline Custo & Vantagem & Tempo \\
\hline $\begin{array}{l}\text { Ferramentas para } \\
\text { Desenvolver a mente }\end{array}$ & Tecnologia & $\begin{array}{l}\text { Ferramentas para Desenvolver a } \\
\text { Colaboração }\end{array}$ \\
\hline Homogenia & Força de trabalho & Diversa \\
\hline Funções de trabalho separadas & Processo de Trabalho & Equipes de Trab. interfuncionais \\
\hline Segurança & Expectativas do Funcionário & Desenvolvimento Pessoal \\
\hline Tarefa das IES & Educação \& Treinamento & $\begin{array}{l}\text { América Corporativa mais um } \\
\text { leque de Empresas Educacionais } \\
\text { com fins lucrativos. }\end{array}$ \\
\hline
\end{tabular}

Quadro 3.1 mostra as diferenças entre o modelo antigo de empresa e a do século XXI - Extraído da (C) 1997 Corporate University Xchange, Inc. citado por Meister (1999).

Para Allen (2007, p.3) UC não é um extravagante departamento de treinamento, a melhor maneira para se distingui-los é só olhar para a variedade de atividades que cada um oferece. Um departamento tradicional de treinamento realiza apenas treinamentos enquanto uma UC realiza treinamentos e muitas outras atividades. A UC tem por objetivo principal adequar as competências individuais às estratégias empresariais. Este objetivo é muito mais abrangente e duradouro do que o objetivo de um simples departamento.

As UCs são responsáveis pelo desenvolvimento de pessoas e pelo crescimento das aptidões de uma organização. Allen (2007, p.6) apresenta algumas atividades que a UC poderá estar envolvida, entre elas: desenvolver e implantar programas de treinamento; avaliar tecnologias; implantar $e$ learning ou programas combinados; contratar vendedores; gerenciar o relacionamento de vendedores; disponibilizar programas de treinamento interna e externamente à empresa; avaliar programas; avaliar a UC; gerir de parcerias; coaching de executivos; tutoria ou mentoring; definir plano de carreira; contratação estratégica; orientar a novos empregados; definir plano de sucessão; mudança de cultura; mudança estratégica; gestão do conhecimento; gestão da sabedoria; biblioteca e coleção eletrônica de informação e pesquisa e desenvolvimento. Esta lista mostra, em outras palavras, que existem várias maneiras de se desenvolver pessoas além de treinamento.

Meister in Eboli (2004) afirma que a UC traz o colaborador para um envolvimento maior com a organização, com a estratégia, com as várias áreas da organização, enquanto que os centros de treinamentos focam $o$ colaborador de uma forma individual. O quadro 3.2 apresenta de forma sumarizada esta mudança de paradigma dos centros de treinamento para universidade corporativa. 


\begin{tabular}{|l|l|l|}
\hline \multicolumn{2}{|l|}{ Mudança de Paradigma } \\
\hline Centro de treinamento & Objetivo & Desenvolver as competências críticas \\
\hline Desenvolver Habilidades & Foco & Aprendizado organizacional \\
\hline Aprendizado Individual & Escopo & Estratégico \\
\hline Tático & Enfase & Estratégias de negócios \\
\hline Necessidades Individuais & Público & Interno e externo \\
\hline Interno & Local & Espaço real e virtual \\
\hline Espaço real & Resultado & Aumento da competitividade \\
\hline Aumento das habilidades & Eucriva \\
\hline
\end{tabular}

Quadro 3.2 - Mudança de paradigma dos centros de treinamento para EC - extraído e adaptado de Meister in Eboli (2004).

Allen (2002, p.4) classifica universidade corporativa em 4 níveis, a saber: o primeiro nível, treinamento, onde as habilidades para tarefas específicas são focadas; seguido pelo nível 2, treinamento e desenvolvimento gerencial, neste nível, além do treinamento oferece, também, cursos para o desenvolvimento gerencial de executivos, que estão preparados para modificar comportamentos; no nível 3, cursos são oferecidos como créditos acadêmicos. Neste nível as UCs oferecem cursos que são aceitos como créditos acadêmicos, entretanto, poucas empresas oferecem estes cursos por conta da burocracia envolvida, e, finalmente, o nível 4, universidades corporativas oferecem programas de graduação e/ou pós-graduação. Dificilmente uma UC ultrapassa os obstáculos para receber uma autorização e trabalhar como se fosse uma universidade tradicional.

\section{A Gestão do Conhecimento}

Conceitos básicos a respeito de dado, informação e conhecimento são necessários para que possamos melhor compreender a Gestão do Conhecimento. De acordo com Davenport (1998, p.18), dados são observações do estado do mundo, podem ser facilmente estruturados, obtidos por máquinas, quantificados, transferíveis e processados por computadores. Dado pode ser descrito por meio de representações formais. Imagens, sons e animações também são considerados dados. Por exemplo: dados de uma pessoa como nome, sexo e naturalidade ou, ainda, temperatura ambiente (facilmente medido por máquina). Informação é o dado trabalhado, num determinado contexto, um conjunto de dados relacionados entre si, por exemplo, temperatura da sala de aula. De acordo com o autor, informação é um conjunto de dados dotados de relevância e propósito, requer unidade de análise, exige consenso sobre o seu significado e exige necessariamente medição humana. Já, o termo conhecimento, para Davenport, é a informação valiosa da mente humana, que inclui reflexão, síntese e contexto, de difícil estruturação, de difícil obtenção por máquinas, e por ser frequentemente tácito, é de difícil transferência. $\mathrm{O}$ conhecimento no meio empresarial envolve a percepção sistematizada do que existe (aprendizado do passado e experiências semelhantes). $\mathrm{O}$ conhecimento envolve, também, o aprendizado e o contínuo refinamento das noções do ambiente estudado. Atualmente o sucesso de uma organização está mais centrado no conhecimento organizacional e no conhecimento individual de cada colaborador do que nos ativos que ela possui. O maior desafio está em administrar este conhecimento; para tanto é necessário, num primeiro momento, identificar o conhecimento 
necessário para o negócio, extraí-lo, democratizá-lo e posteriormente fomentá-lo.

Para Eboli (2004) um dado pode ser transformado em conhecimento seguindo a cadeia do conhecimento. A figura 4.1 mostra que os dados num banco de dados podem ser processados gerando informação; esta, por sua vez, pode ser analisada, originando o conhecimento, este comunicado gera inteligência e a possibilidade do uso numa aplicação cuja execução será decidida (aplicação do conhecimento).

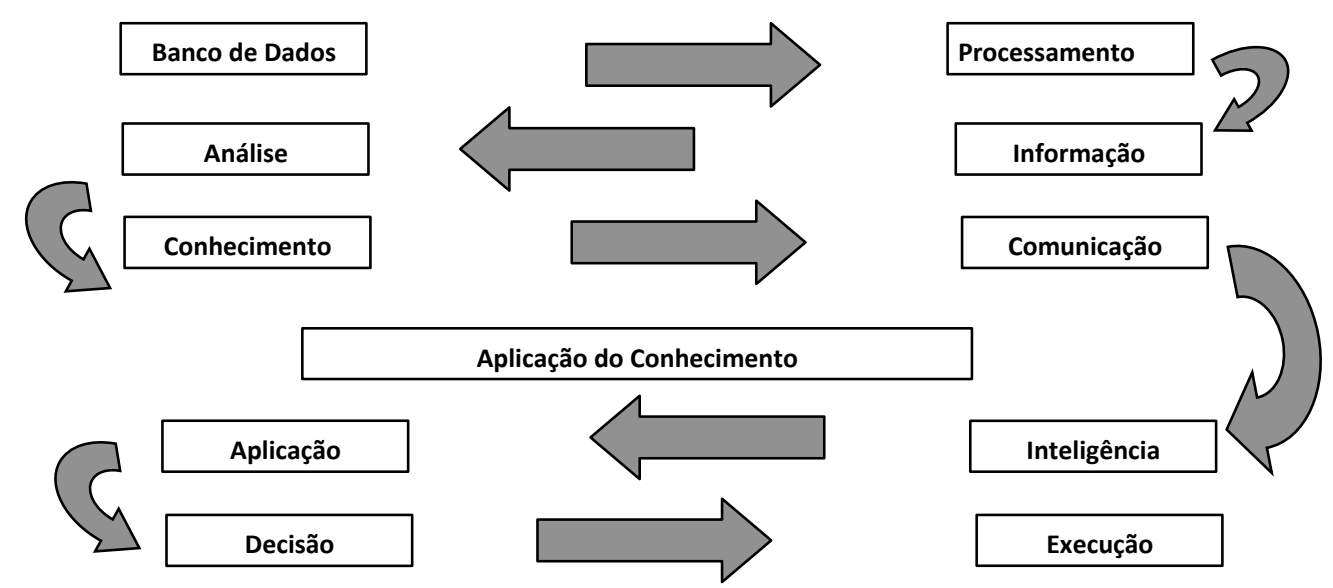

Figura 4.1- Cadeia do Conhecimento - Eboli (2004)

Nos serviços, mais do que na indústria, este conhecimento organizacional e individual é realçado, entretanto, é tão crítico para a instituição de serviço como é para indústria. $\mathrm{O}$ produto carrega consigo a cultura e a inteligência da empresa, além da competência essencial que nem sempre é identificada e administrada por seus colaboradores. $\mathrm{O}$ valor do produto não está na soma de cada uma das partes que o compõem, mas sim no intelecto de quem o produz.

O conhecimento é que faz a grande diferença nas fábricas de software, nos bancos, nas consultorias, mas o grande desafio está em internalizar na organização este conhecimento que aparece no indivíduo colaborador. $\mathrm{Na}$ indústria, esta demanda não é menor, principalmente nas áreas de pesquisa e desenvolvimento, por exemplo. Quin et al apud Klein (1998, p.130) conclui que o intelecto de uma organização funciona em quatro níveis, a saber: o primeiro, o conhecimento cognitivo que é o conhecimento básico e essencial conseguido através de treinamento; o segundo nível, as habilidades avançadas que de acordo com os autores é a "capacidade de aplicar as regras de uma disciplina a problemas complexos"; o terceiro nível, a compreensão dos sistemas, que trata do conhecimento abrangente, uma visão sistêmica de "causa e efeito de uma disciplina" Neste nível os colaboradores vão além da simples execução de processos, possuem profundo conhecimento de área, dos problemas e das consequências e, por fim, o quarto nível, a criatividade auto motivada que, conforme o autor, é a "vontade, motivação e adaptabilidade para o sucesso."

Bateson apud Nonaka e Takeuchi (1997, p. 67) afirma que o conhecimento tácito está associado à experiência e à subjetividade, enquanto que o conhecimento explícito é racional e objetivo. As distinções entre os dois tipos de conhecimento, o tácito e o explícito, são apresentadas na figura 4.2. 
CONHECIMENTO

\begin{tabular}{|c|c|}
\hline $\begin{array}{c}\text { Tácito } \\
\text { (Subjetivo) }\end{array}$ & $\begin{array}{c}\text { Explícito } \\
\text { (Objetivo) }\end{array}$ \\
\hline Conhecimento da experiência (corpo) & Conhecimento da racionalidade (mente) \\
\hline Conhecimento do simultâneo (aqui e agora) & Conhecimento sequencial (lá e então) \\
\hline Conhecimento análogo (prática) & Conhecimento digital (teoria) \\
\hline
\end{tabular}

Figura 4.2 - Dois tipos de conhecimento. Extraído e adaptado de Nonaka e Takeuchi (1997, p.67)

O conhecimento pode ser transmigrado e Nonaka e Takeuchi (1997, p.68) apresenta quatro modos de conversão do conhecimento: a) o conhecimento tácito quando é convertido em conhecimento tácito, é chamado pelos autores de socialização; b) o conhecimento tácito em conhecimento explícito é denominado externalização; c) o conhecimento explícito em conhecimento explícito, chamado de combinação e d) o conhecimento explícito em conhecimento tácito, denominado de internalização. Os autores assumem que o conhecimento é criado pela interação entre o conhecimento tácito e o conhecimento explícito. A figura 4.3 ilustra os quatro modos de conversão do conhecimento.
Conhecimento tácito

Conhecimento tácito

Conhecimento explícito

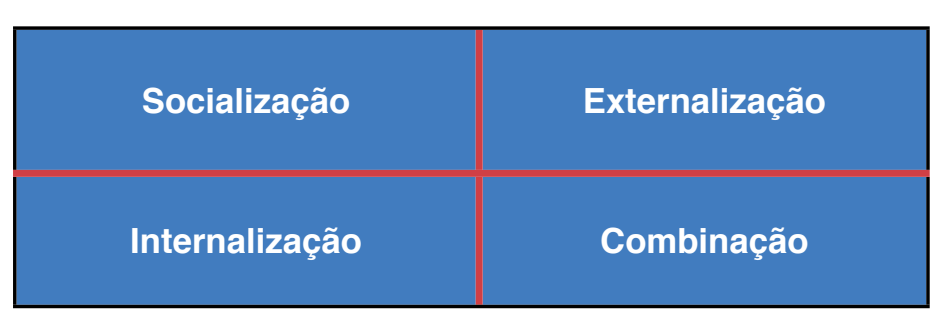

Figura 4.3. Quatro modos de conversão do conhecimento. Extraído e adaptado de Nonaka e Takeuchi (1997,p. 69)

Nonaka e Takeuchi (1997, p.69) consideram socialização como o compartilhamento de experiências, isto é a transferência do conhecimento tácito em conhecimento tácito. Os iniciantes aprendizes aprendem o trabalho não através da linguagem dos seus mestres mas através da observação imitação e prática. Ainda para os mesmos autores, a externalização é um processo de articulação do conhecimento tácito em conhecimentos explícitos. A escrita é uma forma de converter o conhecimento tácito em conhecimento explícito. Uma imagem, por exemplo, é conceitualizada através da linguagem. Combinação, para Nonaka e
Takeuchi (1997, p.75) é o conhecimento formal e estruturado sendo transferido. É a troca, a combinação do conhecimento por meio de reuniões, documentos, redes de computadores. Nas escolas e faculdades o conhecimento, normalmente, é transferido desta forma. E finalmente para os autores internalização é a incorporação do conhecimento explícito no conhecimento tácito, está relacionada ao "aprender fazendo". As experiências através da socialização, externalização e combinação se tornam valiosos ativos quando são internalizadas nos 
indivíduos sob modelos mentais ou Know-how técnico compartilhado.

\subsection{Criando conhecimento dentro da organização}

Klein (1998, p.1) afirma que as empresas nos dias de hoje competem numa "economia de conhecimento" e as empresas que crescem com as experiências, são as "organizações que aprendem". Estas empresas que incentivam o capital intelectual veem grande oportunidade de melhoria frente aos concorrentes, e fazem a gestão estratégica do capital intelectual - estas empresas sabem que "conhecimento é poder". Estas empresas incentivam o desenvolvimento e o compartilhamento de conhecimento. Empresas que têm como estratégia o fomento do capital intelectual devem ter iniciativas / ações no nível operacional, coletando e lapidando ideias e informações colhidas no diadia; estas iniciativas envolvem principalmente os recursos humanos, ou seja, colaboradores e tecnologia da informação necessária para a captura, armazenamento e compartilhamento de informações. O grande desafio está em disseminar uma cultura que apoie e incentive o compartilhamento de conhecimento, particularmente, aquele conhecimento que foi adquirido por profissionais fora do ambiente de trabalho, como advogados e engenheiros.

Klein (1998, p.70) afirma que no início de uma organização a a prendizagem organizacional é normalmente o sinônimo ou equivale à aprendizagem individual, reflexo de pequeno grupo de pessoas que lá trabalham. À medida que a organização cresce, aparece a distinção entre aprendizagem individual e organizacional. March e Olsen in Klein (1998, p.73) apresentam na figura 4.4 o modelo de aprendizagem organizacional. Os autores afirmam que ações individuais são baseadas em convicções individuais. A ação organizacional é formada por ações individuais. Se não houver resposta no ambiente, isto significa que as convicções individuais, a ação individual e a ação organizacional permanecem inalteradas. Por outro lado, se houver resposta ambiental, significa que as convicções individuais mudaram, influenciando em todo o resto do círculo.

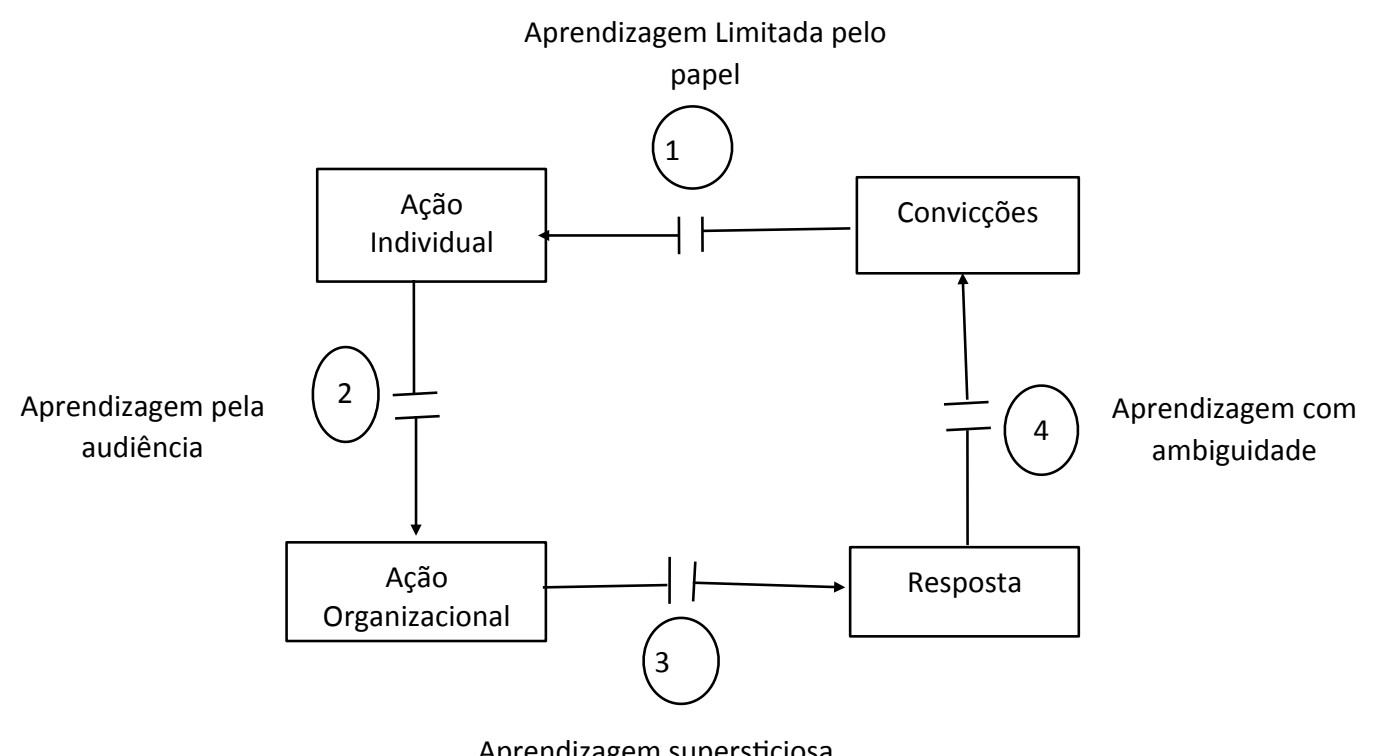

Aprendizagem supersticiosa

Figura 4.4 - Modelo de Aprendizagem Organizacional - extraída e adaptada de March e Olsen in Klein (1998,p73) 
Este modelo, também, aborda os ciclos de aprendizagem incompletos, quando a aprendizagem se prejudica por questões ambientais. São quatro as situações que esse evento pode ocorrer: (1) Aprendizagem limitada pelo papel - acontece quando a aprendizagem individual não tem efeito sobre a ação individual; (2) Aprendizagem pela audiência - quando o indivíduo afeta a organização de forma ambígua; (3) Aprendizagem supersticiosa - o elo entre a ação organizacional e a resposta está rompido (ações são tomadas, a aprendizagem acontece, mas não há uma base real para conectar este dois pontos) e (4) Aprendizagem com ambiguidade - individuo afeta a ação organizacional, que afeta o ambiente e acontece a aprendizagem operacional, mas não a aprendizagem conceitual. É importante que haja um equilíbrio entre essas duas aprendizagens para que a aprendizagem organizacional seja eficaz.

Klein (1998, p.83) afirma que os ciclos de aprendizagem podem não se completar e acabam afetando a aprendizagem organizacional. Os três ciclos incompletos de Kim são: a) aprendizagem situacional, a qual está relacionada às improvisações momentâneas realizadas por indivíduos para resolver problemas que não são codificados para uso posterior, neste caso, nem o indivíduo nem a organização absorvem o aprendizado; b) aprendizagem fragmentada que são situações quando o indivíduo aprende, mas a organização não e, obviamente, quando a organização perde este indivíduo, ela acaba perdendo também; e c) a aprendizagem oportunista, quando algumas tarefas específicas obrigam a organização a realizar os seus procedimentos de forma diferente, uma vez que os estabelecidos não são adequados para a oportunidade. Este compartilhamento do conhecimento, para Allen (2007, p.384), acontece nas discussões da comunidade; nos $e$ - mails / correio eletrônico; nas reuniões presenciais e virtuais e finalmente na tutoria.

\section{A Pesquisa e os resultados alcançados}

A pesquisa foi realizada entre os dez maiores bancos comerciais em operação no país dentre os 156 existentes, segundo dados da Bacen (2007), no período de 7 a 18/04/2008, na cidade de São Paulo. Dos dez maiores bancos contatados oito responderam ao questionário e apenas dois se negaram a respondê-lo, alegando "deliberação interna", ou seja a instituição bancária não responde a pesquisas externas. Entre os bancos respondentes, pelo menos cinco responderam sem colocar grandes empecilhos os outros três tiveram que pedir orientação e permissão a superiores ou a assessoria de imprensa. Isto significa que a metade dos bancos contatados não impôs restrições na divulgação do andamento das suas atividades internas ao mercado, com relação ao tema. Para o leitor interessado no detalhamento desta pesquisa sugiro acessa-la em http://www.unisantos.br/ upload/menu3niveis_1258487935688_2008_te xto_completo_paulo_roberto_alves.pdf. Reservo este espaço para a apresentação de uma análise geral desta averiguação acadêmica.

O objetivo geral desta pesquisa era identificar o quanto a prática da educação corporativa (EC) influencia na gestão do conhecimento em empresas do setor financeiro localizadas na cidade de São Paulo e apresentar de forma descritiva, o resultado encontrado, com o uso de uma pesquisa quantitativa e com coleta de dados por meio de questionários. Somente os bancos que possuem UC têm também GC implantada de forma estruturada. Apesar da representatividade dentro do universo pesquisado, quase 40 por cento (tem UC formalmente constituída), dentro de um 
universo maior, ou seja, o número de bancos em operação no país, estes bancos que possuem UC e GC implantadas representam pouco mais de 1 por cento. Entretanto, dito pelos respondentes que a $\mathrm{UC}$ auxiliou em muito a implantação da GC, ambas as práticas são bastante recentes entre os pesquisados. Além disso, a confirmação dos respondentes afirmando que houve a contribuição da UC na GC, explicitado várias vezes durante a pesquisa que a GC muito se beneficiou após a implantação das UC. Nas organizações, dito pelos principais autores pesquisados, particularmente, Davenport (1998) e Nonaka e Takeuchi (1997) uma organização não sobrevive sem informação em se tratando de grandes corporações que tem a UC implementada, esta prática auxilia a catalisar, explicitar, organizar e multiplicar o conhecimento dentro delas de forma estruturada e organizada. A formalidade estruturada da transferência do conhecimento por meio de uma UC facilita a explicitação do conhecimento podendo futuramente ser transferido por meio de treinamentos formais, documentos, normas e procedimentos além de outros meios, assim como o conhecimento tácito pode ser transferido na informalidade entre os envolvidos com a UC e futuramente explicitado. A implantação da GC é influenciada de forma positiva após a implantação da UC e os resultados apontados neste estudo confirmam. Um ambiente formal de conhecimento onde todos os colaboradores têm acesso, que agrega conhecimento a cada participante, também auxilia na diminuição da informalidade da troca de conhecimento. Paradoxalmente, somente os que possuíam UC e GC implantadas reconhecem existência barreiras para a transferência do conhecimento, isto significa dizer que estas duas práticas evidenciam as dificuldades nesta troca de conhecimento. Os participantes da pesquisa que não possuíam UC e GC evidenciaram respostas categóricas que na organização em questão a barreira para a transferência do conhecimento era inexistente.

\section{Considerações finais}

É possível que muitas outras considerações possam ser realizadas, mas as aqui apresentadas, não só se embasam nas análises feitas, mas, também, nas observações realizadas pelo autor nas organizações.

Pode-se considerar, do ponto de vista implementação, que é recomendável a implantação de uma UC antes da estruturação de uma GC, uma vez que esta segunda pode muito se beneficiar. Vale a pena ressaltar que segundo os autores pesquisados, particularmente, Davenport (1998) e Nonaka e Takeuchi (1997), o conhecimento é a alma da organização sem ele a organização não sobreviveria. Esta pesquisa tratou do conhecimento estruturado organizado de forma a melhorar o desempenho e apoiar a estratégia empresarial e as competências essenciais de uma organização. Foi comprovado por ela que a gestão deste conhecimento com o apoio de uma UC, é facilitada por se tratar de um local formal e respeitado por todos os colaboradores para a transferência do conhecimento e por ser mais que um departamento de treinamento. Meister in Eboli (2004) afirma que a UC traz o colaborador para um envolvimento maior com a organização, com a estratégia, com as várias áreas da organização, desta forma auxiliando na estruturação e multiplicação do conhecimento de forma organizada. Allen (2007, p.6) afirma que a GC é uma das atividades que a UC poderá estar envolvida, e esta pesquisa confirma a ocorrência entre os bancos pesquisados e envolvidos, o mesmo autor (p.372) enfatiza o papel da UC na gestão e no compartilhamento do conhecimento. Eboli (2002) reconhece que o conhecimento coletivo e a cultura corporativa devem, também, ser incentivados através da transferência do conhecimento do indivíduo para a cadeia de valor. Por se tratar de um aprendizado organizacional a UC também pode influenciar.

Espera-se que este trabalho tenha contribuído para possibilitar, aos gestores 
bancários, o estabelecimento de um caminho mais fácil para o sucesso dos mesmos. Esperase, também, que este trabalho tenha ampliado a base empírica dos estudos relacionados com a
UC e a GC, uma vez que foi observado, entre o universo pesquisado, que pouco foi realizado nesta área.

\section{Referências Bibliográficas}

ALLEN M. The Corporate University Handbook. New York: Amazon, 2002.

ALLEN M. The Next Generation of Corporate University. São Francisco: Pfeiffer, 2007.

ARGYRIS, C. On organizational learning. Oxford: Blackwell, 1996.

BACEN - Banco Central do Brasil, Disponível em: <http://www.bcb.gov.br/htms/deorf/r200712/ T1ES_Quadro\%2001\%20-\%20Quantitativo\%20de\%20instituições\%20autorizadas\%20a \%20funcionar.pdf $>$ Acesso para atualização dos dados em 08 nov. 2011.

BAYMA, F. Educação e mercado de trabalho. Dissertação (Pós-graduação). Campinas: Papirus, 1994.

DAVENPORT, T. H. Ecologia da Informação: por que só a tecnologia não basta para o sucesso na era da informação. São Paulo: Futura. 1998

DREJER, A. Organisational learning and competence development, The Learning Organisation, Vol. 7, No. 4, pp.206-220, 2000.

EBOLI, M. Educação corporativa no Brasil Mitos e Verdades. São Paulo: Gente. 2004.

FEBRABAN, 2008, Disponível em: <http://www.febraban.org.br>Acesso em 11 fev. 2008.

FEBRABAN, 2009, Relatório Anual, Disponível em: <http://www.febraban.org.br/p5a_52gt34+ $+5 \mathrm{cv} 8$ _4466+ff145afbb52ffrtg33fe36455li5411pp+e/sitefebraban/Febraban_completo.pdf $>$ Acesso em: 08 nov. 2011.

KLEIN, D. A. A Gestão Estratégica do Capital Intelectual. Rio de Janeiro:Quality Mark. 1998.

MEISTER, J. C. Educação Corporativa: A gestão do Capital Intelectual através das Universidades Corporativas. São Paulo: Pearson Makron Books. 1999.

MORIN, E. A Complexidade e a Empresa. Publicado no Caderno de Leitura do CPE - Curso Preparatório de Educadores, extraído do tomo The Generation Of Scientific, Administrative Knowledge, editado por Michel Audet e Jean-louis Maloin, Presses de I'Université Laval, Quebec, 1986, pp.135-154. Universidade Corporativa Banco do Brasil. Brasília, 2004.

NONAKA, I; TAKEUCHI, H. Criação de Conhecimento na Empresa. Rio de Janeiro: Campus. 1997.

SOUZA, C. Talentos e competitividade. Rio de Janeiro: Qualitymark. 2000. 